\title{
In Back of Nishida-san
}

\author{
$\operatorname{AUTHOR}(S)$ :
}

Ihobe, Hiroshi

\section{CITATION:}

Ihobe, Hiroshi. In Back of Nishida-san. Pan Africa News 2011, 18(special issue): 8-8

\section{ISSUE DATE:}

2011-09

URL:

http://hdl.handle.net/2433/147283

RIGHT:

Copyright (C) Pan Africa News. 
would be alright. After all, chickens were raised in a special way for such consumption in Japan, where they were a delicacy. But I doubt that the chicken we ate that night in Kansyana camp was raised in the same way in Kasiha village!

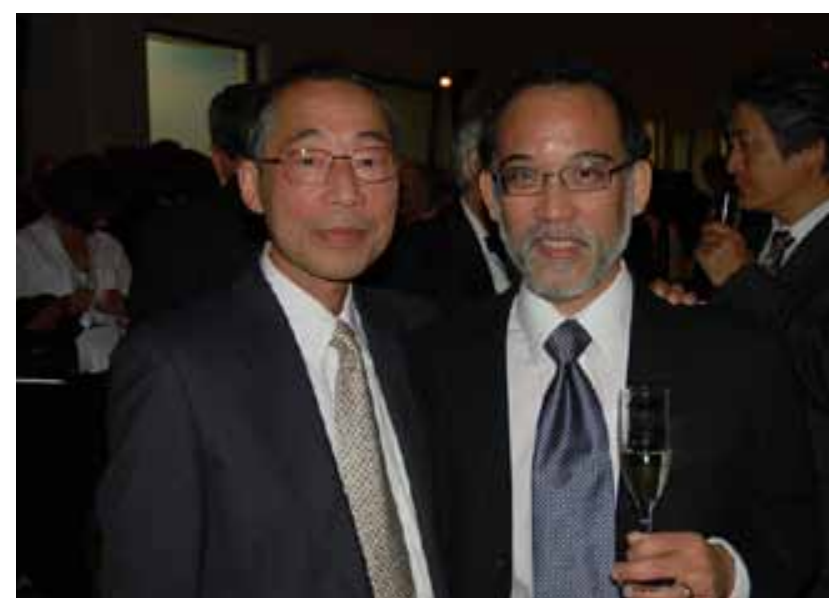

In the end, ours was a remarkable friendship. Those were in fact his last words to me in an email message he sent before he passed away. I wasn't aware at the time that this would be our last communication. Toshi was always quite stoic and never let on how much he must have been suffering, at least to me. I will remember his strength of character and the strength of our friendship, built on trust and mutual respect and admiration. I miss him greatly.

\section{A Memory of Toshisada Nishida}

\section{Craig Stanford \\ University of Southern California, USA}

I first met Toshisada Nishida in October 1991, when I visited him at his research camp in Mahale National Park. We had corresponded for some months and although I was relatively new in the chimpanzee research world, he graciously invited me to spend a week with him on a holiday from fieldwork at Gombe. To get to know him in the field and to tag along on his daily follows of the Mahale chimpanzees, with the team of assistants and students he had trained over the years, was truly awe-inspiring. One memorable wet day we sat watching the chimps doing a rain dance in a downpour so heavy I thought surely the hillside on which we sat would surely be washed away. Only when Dr. Nishida decided the weather would not allow further observations - by now streams of flood water were racing around our legs-did we return to camp. I learned that beyond his primatological wisdom, he knew which mushrooms were delicious and which were poisonous, and which fish from Lake Tanganyika made the best sushi.

Although I touched base with Dr. Nishida at the IPS Congress in Kyoto in 2010, not knowing he was ill at the time, my last vivid memory of him and his impact on our field is his retirement banquet and lecture, held in Kyoto in 2004. I was lucky enough to be among the group of foreign chimp-ologists invited to attend. We were treated royally. The highlight was observing the honorifics bestowed upon Dr. Nishida by so many hundreds of his aca- demic peers.

The world has lost one of the greatest primatologists in the history of our discipline. We must be grateful for his enormous contributions and for the legacy he leaves to future generations of both Japanese and western students of animal behavior.

\section{In Back of Nishida-san}

\section{Hiroshi Ihobe \\ Sugiyama Jogakuen University, Japan}

I am writing this tribute at Mahale. I first came here nine years ago in 1995 and stayed with Nishida-san for several months. I was fortunate to have been able to conduct research at field sites with three famous Japanese fieldworkers. When I was an undergraduate student, I followed Itani-san to Kuchinoshima Island in Japan to study feral cattle. As a graduate student, I went to Wamba in the former Zaire and walked with Kano-san in the forests there to study pygmy chimpanzees. And I spent time with Nishida-san at Mahale. Each field worker has his style. Itani-san wrote "Haiku" in the field and showed it to me while observing cattle. Kano-san did not speak to me often, and I only followed him from behind as we walked in the forest. Nishida-san recorded how chimpanzee foods tasted by eating them. I think Itani-san and Kanosan were generalists and Nishida-san was a specialist. Nishida-san's interest was focused entirely on chimpanzees. He seemed to try to understand the environment through the eyes of the chimpanzees. All three fieldworkers, however, have common features. They did not teach me many things directly. Instead, I learned the way to conduct fieldwork by following them in the field. While following them, I observed their manners and experienced how to carry out fieldwork successfully. While I followed Nishida-san, I came to learn many important things about Mahale. His death has left a deep hole and is a big loss for Japanese primatology. I wish I could follow him from behind to Mahale once more because I still have to learn many things about there and about fieldwork. This, however, is an impossible dream for now. I can honor his soul by working hard to emulate him in the field, but it is too hard to equal him when it comes to fieldwork.

\section{Short Tribute}

\author{
Miho Nakamura \\ ANC Productions Inc./Kyoto Unviersity, Japan
}

Remember, he was speaking fast about the classification of Hominidae in the first class of primatology, I was just 20 years old then. Remember, he took a picture of a Japanese macaque showing threat while I was provoking the female, then I realized how much I get excited in the field. Remember, we climbed a cliff of the Mahale mountains only to discover a breathtaking view. We couldn't catch up the chimpanzees but he looked happy and satisfied with the view. Dr. Nishida, always young in spirit, loves to visit a new place as well as deepening his scientific knowledge. 